\title{
Family Relationships and Children's Emotional Adjustment as Correlates of Maternal and Paternal Differential Treatment: A Replication with Toddler and Preschool Siblings
}

\author{
Brenda L. Volling and Julie L. Elins
}

\begin{abstract}
Recent behavioral genetic research emphasizes the nonshared family environment as an important contributor to psychological differences between siblings raised in the same family. Most studies of nonshared sibling experiences have examined the effects of differential maternal and paternal treatment separately and have not examined family-level processes. This study attempted to replicate the findings of McHale, Crouter, McGuire, and Updegraff and also of Volling in which relations between family patterns of differential parental treatment, child outcomes, and family functioning were examined. Questionnaire data were collected from 60 maritally intact families with toddler and preschool siblings. Congruence in mothers' and fathers' reports of differential treatment (i.e., similar treatment from both mother and father) was most frequent. Parents' reports of differential enjoyment were related to differential favoritism, whereas their reports of differential discipline were not. Both mothers and fathers were more likely to discipline the older sibling than the younger toddler. Sibling and marital harmony characterized families in which the father disciplined the older sibling more and mothers disciplined the two children equally. Incongruent patterns of differential favoritism (i.e., one parent treats the children equally while the other favors one child) were associated with marital distress. Preschool siblings exhibited greater internalizing and externalizing symptoms when both mothers and fathers disciplined them more than their younger sibling. The findings of this study with very young siblings differ in some respects from those with older children and suggest that future research needs to examine differential parental treatment as a developmental process across childhood.
\end{abstract}

\section{INTRODUCTION}

Current behavioral genetic research has emphasized that siblings raised within the same family are often as different from one another with regard to personality, psychopathology, and behavior problems as children raised in different families (Daniels, Dunn, Furstenberg, \& Plomin, 1985; Daniels \& Plomin, 1985; Dunn \& Stocker, 1989; Plomin \& Daniels, 1987). Plomin and Daniels (1987) have noted that sibling differences are more than likely due to environmental variability and, particularly, the nonshared environment (i.e., aspects of the environment experienced differently by siblings). Nonshared family experiences include differential parental treatment (i.e., how parents treat the two children in relation to one another) and differential sibling interaction (i.e., siblings provide different interactive environments for one another).

In an effort to examine nonshared family influences, most research has focused on differential parental treatment in accounting for differences between siblings with respect to developmental and behavioral outcomes (Conger \& Conger, 1994; Dunn, Stocker, \& Plomin, 1990; McGuire, Dunn, \& Plomin, 1995; Stocker, 1993). Much of the early work in this area has focused on how mothers treat the two siblings differently and has found that not only is differential maternal treatment related to greater conflict and hostility between siblings (Brody, Stoneman, \& Burke, 1987; Bryant \& Crockenberg, 1980; Hetherington, 1988; Stocker, Dunn, \& Plomin, 1989), but also to greater adjustment difficulties for the "less favored" child (Dunn et al., 1990; McGuire et al., 1995; Stocker, 1993). Several recent efforts have included fathers in their studies of nonshared environmental influences and have noted that differential paternal treatment is also related to the quality of sibling interaction (Brody, Stoneman, \& McCoy, 1992; Volling \& Belsky, 1992) and sibling adjustment outcomes (Stocker, 1995). Interestingly, Brody et al. (1992) reported that differential paternal treatment continued to explain unique variance in sibling relationship quality once differential maternal treatment had been controlled. Thus, future work needs to examine the links between maternal and paternal behavior with sibling relationships and adjustment outcomes to capture the full realm of nonshared family experiences.

Even though both mothers and fathers are now be-

(C) 1998 by the Society for Research in Child Development, Inc. All rights reserved. 0009-3920/98/6906-0010\$01.00 
ing included in studies of differential treatment, most of the work in this area still examines the effects of differential maternal treatment independently from those of differential paternal treatment (Brody et al., 1992; Volling \& Belsky, 1992). Granted, important information has been obtained by knowing that what fathers do with their children is also an important component of the nonshared environment. Yet it may be more insightful when including both mothers and fathers in nonshared environment studies to examine family patterns of differential treatment, in other words, to identify families in which the behavior of both parents is taken into account simultaneously. It is quite possible that growing up in a family in which both parents favor the same sibling is a very different experience than growing up in a family where the mother favors one sibling and the father favors the other sibling.

McHale, Crouter, McGuire, and Updegraff (1995) were the first to take this into account and consider family patterns of differential parental treatment across mothers and fathers in a sample of school-age children and adolescents. They identified families as falling into three groups according to the parents' differential treatment: (1) congruent patterns, in which both parents displayed a similar pattern of treatment (e.g., both treated the children equally or both directed more behavior to the older child); (2) complementary patterns, in which one parent directed more of a given behavior to one sibling and the other parent directed more of a given behavior to the other sibling; and finally (3) incongruent patterns, in which one parent directed more behavior to one child while the other parent reported equal treatment of the siblings. Their findings revealed that the majority of families demonstrated congruent patterns of differential treatment, with a sizable proportion exhibiting incongruent behavior patterns, in which one parent treated both children equally, but the other directed more discipline or affection to one sibling, almost always the younger in this case. The complementary pattern was extremely rare.

Volling (1997) recently completed a similar analysis of family patterns of differential treatment in a sample of preschool siblings between $3^{1 / 2}$ and 6 years of age and found results quite consistent with the McHale et al. findings with older children and adolescents. In particular, congruent family patterns were the most frequent, with complementary patterns extremely rare. Incongruent patterns of differential treatment were also found, but in this case, it almost always took the form of the father disciplining the children equally, while the mother disciplined the older sibling more. Thus, the first goal of this research was to replicate the earlier results of both McHale et al. (1995) and Volling (1997) by identifying familylevel patterns of differential treatment using a sample of younger toddler and preschool siblings $\left(1^{1 / 2}\right.$ to 4 years) to determine whether the configurations of congruent, incongruent, and complementary family patterns were similar or different from those reported in the earlier studies. Angry and resistant child behaviors appear to peak during the second year of life (Kopp, 1992), which is one of the reasons this period has often been referred to as the "terrible twos." Issues of parental control and child compliance are generally the major focus of investigations examining the period of toddlerhood (e.g., Belsky, Woodworth, \& Crnic, 1996; Crockenberg \& Littman, 1990; Kuczynski \& Kochanska, 1990), and it is possible that family configurations of differential parental treatment during this developmental period, particularly those for differential discipline, may look different than those obtained at other ages.

In the McHale et al. (1995) study, as well as the majority of differential treatment studies conducted with children in middle childhood and adolescence, both parents tend to direct more attention, control, and affection to younger siblings in the family in comparison to older siblings (e.g., Brody et al., 1987, 1992; Bryant \& Crockenberg, 1980; Stocker et al., 1989). In addition, most studies not only equate more parental affection and less parental control of one sibling with parental favoritism, but often assume that this differential is detrimental to the formation of cooperative sibling relationships and children's developmental outcomes; in other words, it is often viewed as a "risk factor" (see Rutter, 1987, for a discussion of risk factors). That is, if a parent demonstrates more affection toward one sibling in relation to the other, or controls one sibling less than the other, this is seen as favoring one child over the other, and such favoritism leads to greater hostility and conflict between siblings. In a recent study of differential parental treatment using a sample of preschool siblings, Volling (1997) found that both mothers and fathers were more likely to report equal treatment of their children when asked to report on which child they favored or enjoyed more. In the case of discipline, however, both mothers and fathers reported disciplining the older sibling more often than the younger preschooler in the family. Moreover, fathers' reports of differential favoritism, but not mothers' reports, were associated with their reports of enjoyment, so it seemed that fathers did favor the child they also enjoyed more often. However, neither 
mothers' nor fathers' reports of differential discipline were related to their reports of differential favoritism, suggesting that when parents disciplined the older preschool child, they did not view this as favoring the younger child. Volling (1997) argued that disciplining a physically stronger and more cognitively advanced older sibling during conflict with a younger, more vulnerable toddler is probably not a sign of parental favoritism, but may be an effective and appropriate parenting strategy in the period of early childhood, where a 2 to 3 year age difference between siblings reflects a substantial difference in the children's developmental capabilities. Indeed, the older sibling's emotionally disruptive behavior during this time may elicit more parental discipline, as parents are more than likely expecting their older children to evince better self-regulation skills than the younger siblings (Kopp, 1982). Thus, the second aim of the current study was to examine in an independent sample of toddler and preschool siblings, approximately 2 years younger than those studied by Volling (1997), whether parents discipline and enjoy the younger sibling more often, as is often reported in studies with older children in middle childhood and adolescence, or direct more of a given behavior to the older sibling, particularly discipline, in the period of early childhood. A third, related aim was to examine the associations between parents' reports of differential favoritism, differential enjoyment, and differential discipline to see whether less discipline and more enjoyment are considered by parents of these young children to reflect parental favoritism of one child over another. Based on the earlier findings, it was anticipated that significant associations would be found for both mothers and fathers between differential enjoyment and favoritism, but not between differential discipline and favoritism.

The final goal of this research was to replicate findings reported by both McHale et al. (1995) and Volling (1997) regarding family relationship quality and children's adjustment as a function of the family patterns of differential treatment. The investigation of family and child functioning from such a perspective is important for several reasons. First, it provides a means of examining family functioning that cannot be assessed by examining the separate effects of differential maternal and paternal treatment. For instance, differential maternal control may indeed be related to greater sibling hostility and child behavior problems, but the developmental consequences for children in families where mother controls the older more and father also controls the older child more often may be very different than in those families where mother uses more control with one child and the father controls the children equally, or actually controls the other sibling more often. Considering family-level patterns of differential treatment allows us to ask questions surrounding the buffering effects of relationships and to identify which children may be most at risk for developing psychopathology (Rutter, 1987). For instance, are children who are controlled by both parents more at risk than those controlled by only one parent or by neither parent?

In a family-level analysis, McHale and her colleagues reported that younger school-age siblings seemed to be more reactive to preferential treatment in that younger siblings who received more affection than their older sibling reported greater self-worth and satisfaction in their parent-child relationships, but reported more anxiety, more sibling hostility, and were less satisfied with their parent-child relationships when receiving more discipline from both parents than when the older sibling was disciplined more often by both parents. Also, children who were disciplined more often by both mothers and fathers, regardless of whether they were the younger or older sibling, were also rated more negatively in their interactions with a sibling than those treated equally by both parents. Interestingly, older siblings reported higher self-worth under conditions of equal affection, not when more affection was directed to them by both mothers and fathers, and actually reported more warmth in their sibling relationships when they were the recipients of more discipline by both parents. Older and younger children in the same family are clearly not reacting to similar patterns of differential treatment in the same way, and it is not clear as yet what role the children's ages and developmental levels may play in explaining these differences.

Volling (1997) also reported different family relationship correlates of incongruent and congruent family patterns in early childhood. In this case, mothers reported more rivalry and less positive involvement on the part of the older sibling if mothers favored the younger sibling more and fathers favored the siblings equally than if both parents favored the children equally. Spouses in these incongruent families also reported less marital love. On the other hand, congruent families in which both parents disciplined the older sibling more had the most positive family correlates when compared with the other congruent pattern in which both parents disciplined the children equally. In this case, fathers were more socially involved with older siblings, younger siblings initiated less sibling conflict, and spouses reported less marital conflict and ambivalence than in families where both parents disciplined the two children equally. Therefore, a family-level analysis revealed 
that it was not always the case that when one child received more discipline than the other child that differential treatment was associated with family conflict or problematic child behavior. The current study attempts to extend this earlier work by examining whether similar family dynamics characterize congruent and incongruent family types in families with very young children or whether the developmental periods under investigation (e.g., early childhood versus adolescence) across studies might in some way influence the nature of family relationships and, in turn, children's emotional functioning.

A second reason for examining family-level patterns of differential treatment is that it allows researchers to investigate family systems processes that have not been adequately addressed in the differential parental treatment literature. Family systems theorists have long hypothesized that trouble in the marital subsystem may result in a cross-generation alliance between a parent and one child in the family against the other parent. Such family dynamics are thought to have severe repercussions for the child's psychological well-being (Christensen \& Margolin, 1988; Haley, 1967; Minuchin, 1974). Minuchin (1974) believed that these covert alliances led to childhood disturbances for the child triangulated in this system by (1) creating anxiety for the child as a result of being forced to side with one parent against the other, (2) creating conflict and confusion for the child as a result of misplaced power against the nonaligned spouse, (3) inhibiting social development with peers because of the overinvolvement with the parent, and (4) contributing to conduct problems as a result of a weakened spousal alliance that undermined the parents' authority to discipline the child.

Several recent investigators have suggested that differential parental treatment patterns might reflect a family system in which a parent-child alliance has formed as a result of marital distress (Brody, Stoneman, \& McCoy, 1994; Deal, 1996; McHale et al., 1995; Reiss et al., 1994; Volling, 1997). Significant associations have been found between mothers' and fathers' differential parental treatment and marital adjustment (Brody et al., 1994; Deal, 1996). In addition, both McHale et al. (1995) and Volling (1997) reported that incongruent family patterns of differential affection or differential favoritism were associated with spousal reports of less marital love. There was, however, no significant relation between incongruent patterns of differential discipline and marital functioning in either study. Thus, it appears that showing favoritism or more affection disproportionately to one sibling may indicate the formation of a parent-child coalition and marital distress, whereas doling out discipline differentially across two different-aged children may not reflect marital difficulties, but an appropriate child-rearing strategy. This poses an interesting question that the current research hopes to address: When does differential parental treatment reflect distress in the family system and when does it reflect a normative parenting strategy?

Given the earlier reports of McHale et al. (1995) and Volling (1997), it was anticipated that incongruent patterns of differential favoritism and enjoyment, which might indicate that a parent-child coalition with one parent has been formed against the other, would be related to more conflicted marital relationships and greater emotional dysregulation for children. Specific hypotheses regarding the links between family and child functioning, and patterns of differential discipline, were not as straightforward. Given the extant literature suggesting that siblings appear to benefit from equal treatment, whereas differential parental treatment is related to greater conflict in the sibling relationship and child adjustment problems, one might hypothesize that congruent patterns reflecting equal discipline of siblings would be associated with more positive family and child outcomes than incongruent patterns. Yet findings from McHale et al. (1995) and Volling (1997) suggest that the picture may be a bit more complicated. If disciplining children differently during the preschool period is considered an appropriate childrearing strategy, wherein older siblings need more control than a younger sibling, then signs of marital and family distress would not be expected to characterize either incongruent family patterns of differential discipline in which older siblings are disciplined more, or congruent patterns where the older sibling is disciplined more by both parents. In contrast, if differential discipline is viewed as a risk factor, consistent with the view of many prior studies, then those older siblings who are disciplined more often by both mothers and fathers (a congruent pattern) might be those family situations that give rise to more family conflict and greater problematic child behavior. This is based on notions emanating from a cumulative risk model which proposes that children's development is compromised when there is an accumulation of risk factors (see Sameroff \& Seifer, 1983). Because of the limited availability of research addressing the links between marital relations and differential treatment in early childhood, these analyses will necessarily be more exploratory in nature.

In summary, this study was aimed at the following four goals: (1) to identify the various family patterns of differential enjoyment, favoritism, and discipline within families with young siblings; (2) to determine 
if parents of toddler- and preschool-age children direct more behavior to younger siblings in the family, as has been reported in studies with children in middle childhood and adolescence; (3) to determine if differential favoritism is associated with parents' reports of differential discipline and enjoyment; and, finally, (4) to examine family relationship quality and children's emotional adjustment as correlates of family patterns of differential parental treatment in an effort to replicate earlier findings.

\section{METHOD}

\section{Participants}

The participants for this study included mothers, fathers, and sibling dyads from 62 maritally intact families who were participating in a short-term, longitudinal study of parent-child and sibling relationships in infancy and early childhood. One family was later dropped from the study due to marital separation, and one family terminated their participation before the sibling assessment. Thus, complete data were available from 60 families. Participants were recruited through follow-ups to birth announcements in the local newspapers and referrals from participating families. Families had to fit three criteria to be considered eligible for participation: (1) families had to be maritally intact, (2) both mothers and fathers had to agree to participate, and (3) there had to be at least two children in the family, with the younger of the two approaching 12 months of age and the older between the ages of 2 and 6 years. Of the eligible families contacted, $69 \%$ agreed to participate. The majority $(93 \%)$ of the couples were European American $(n=56)$, with one Native American couple, and three interracial couples. At the time of data collection, parents were married for an average of 7 years (range $=$ 3-16 years). Fathers were, on average, 35.6 years old, had completed 17.4 years of education, and had a mean income of $\$ 53,759$. Mothers were, on average, 33.2 years old, had completed 16.5 years of education, and had a mean income of $\$ 19,850$. At the time of the sibling data collection, the age of the younger sibling in all families was 16 months, and the mean age of the older sibling was 50 months. The average age difference between siblings was 35 months (range $=11$ 68 months). The majority of infants were second-born $(n=44)$, with the remaining 16 children thirdthrough fifth-born. In the case of families with more than two children, the older sibling closest in age to the 16-month-old child was asked to participate. The sample included 20 girl/girl dyads (older-younger), 14 boy/boy dyads, 10 girl/boy dyads, and 16 boy/ girl dyads.

\section{Procedure}

Families were invited into the university laboratory for three visits when the youngest sibling was 12,13 , and 16 months of age. The main focus of the larger project was to examine the correlates and consequences of mother-infant and father-infant attachment relationships at the end of the infant's first year. As such, the 12 and 13 month visits were counterbalanced assessments of mother-infant and father-infant interaction and are not the source of information for the current study. Measures of the marital relationship and the older siblings' problem behaviors, however, were collected as part of a questionnaire packet sent home with parents after the 12 and 13 month visits. These were then mailed back within 2 weeks following the visits. The 16 month visit involved assessments of dyadic and triadic family interaction based on the work of Teti and Ablard (1989), and were designed to examine the prediction of sibling relations from parent-infant attachment. They are also not the source of data reported here. Questionnaire data assessing each parent's perceptions of their differential treatment and the quality of the sibling relationship were collected during the 16 month visit. All families were paid $\$ 30$ for their participation.

\section{Measures}

Questionnaires were completed by both mothers and fathers and assessed parents' perceptions of their differential treatment, the quality of the sibling and marital relationship, and the older sibling's behavioral adjustment. To be noted is that the differential treatment and marriage scales used in this report were nearly identical to those used by McHale et al. (1995) and Volling (1997), allowing a direct comparison of findings for purposes of replication.

Parents' differential treatment. Mothers and fathers completed the differential parental treatment subscale of the Sibling Inventory of Differential Experience (SIDE; Daniels \& Plomin, 1985) to assess how parents treat the siblings differently. Each parent was asked to rate their treatment of the children in relation to one another on a 5 point Likert scale $(1=$ much more with the older sibling; $2=$ a bit more with the older sibling; $3=$ same; $4=$ a bit more with the younger sibling; $5=$ much more with the younger sibling). Three of the nine SIDE items were used to assess the following dimensions of parental behavior: parents' discipline, favoritism, and enjoyment of the older versus the younger sibling. These items were (1) have disciplined him / her, (2) have tended to favor him/her, and (3) have enjoyed doing things with 
him/her. Three groups of families, similar to those used by McHale et al. (1995) and Volling (1997), were created based on parents' responses: (1) families in which the older sibling received more of a given form of treatment, (2) families in which the younger sibling received more of a given form of treatment, and (3) families in which parents treated both children similarly. ${ }^{1}$ Two week test-retest reliability for the SIDE items was calculated on 19 of the mothers and 22 of the fathers in the sample, with stability coefficients of .77, .73, and .84 for mothers' reports of enjoyment, favoritism, and discipline, respectively, and $.68, .70$, and .52 for fathers' enjoyment, favoritism, and discipline, respectively (all $r$ s significant at $p<$ $.05)$.

Evaluation of the sibling relationship. To assess the older sibling's behavior, mothers and fathers completed 49 items of a modified version of the Sibling Inventory of Behavior (SIB; Schaefer \& Edgerton, 1981), developed by Hetherington and Clingempeel (1992), which has six sibling relationship scales: involvement, empathy, rivalry, avoidance, aggression, and teaching. Because the internal consistency of the avoidance scale for mothers was quite low (.43), the avoidance scales were dropped from further consideration. Two composited measures were created from the remaining five subscales: a 15 item positive involvement scale consisting of the sum of teaching, empathy, and involvement (alpha $=.84, .85$ for mothers and fathers, respectively) and a 12 item conflict scale consisting of the sum of rivalry and aggression (alpha $=.91, .91$ for mothers and fathers, respectively). Because many of the items on the original SIB were considered to be inappropriate for a 16-monthold younger sibling (e.g., makes plans that include the older sibling; babysits and cares for the older sibling), parents completed only 13 items of the SIB and

1. The SIDE items are generally not used in the manner reported here, but rather, the nine original items are averaged to create two continuous scales: a five item differential parental affection scale and a four item differential parental control scale. Analyses with the two continuous scales for both mothers and fathers do not permit an adequate examination of the family patterns of differential treatment, nor whether parental favoritism is associated with parents' reports of differential discipline and differential enjoyment. In addition, alphas for the SIDE scales suggested moderate internal consistency for differential paternal control (.74), differential paternal affection (.74), and differential maternal control $(.78)$, whereas the differential maternal affection scale was unreliable (.37). Correlations conducted between mothers' and fathers' differential affection and control were all nonsignificant, suggesting that parents are not only inconsistent in their treatment of young siblings, but that there is a strong possibility that congruent, incongruent, and complementary patterns of differential parental treatment characterize these families.
18 items from the Sibling Relationships in Early Childhood Questionnaire (Volling, 1997). Intercorrelations between these items were examined and revealed two internally consistent dimensions for the younger siblings' behavior that corresponded closely to the two dimensions for the older sibling: (1) an eight item positive involvement scale (alpha $=.86, .76$ for mothers and fathers, respectively) and (2) a seven item conflict scale (alpha $=.73, .61$ for mothers and fathers, respectively). Sample items for each scale included "treats younger sibling as a good friend" (older sibling positive involvement), "is very competitive against younger sibling" (older sibling conflict), "has fun or a good time with brother/sister" (younger sibling positive involvement), and "has physical fights with older sibling, not just for fun" (younger sibling conflict).

Assessment of the marital relationship. Husbands and wives completed the Braiker and Kelley (1979) Intimate Relations Scale. This 25 item questionnaire assessed four interpersonal aspects of the marital relationship: (1) maintenance-the extent to which spouses attempt to enrich, improve, and maintain their relationship (alpha $=.78, .75$ for wives and husbands, respectively); (2) conflict - the extent to which couples engaged in marital disputes (alpha $=.79, .86$ for wives and husbands, respectively), (3) love-the extent to which spouses report feelings of love for one another (alpha $=.92, .93$ for wives and husbands, respectively), and (4) ambivalence-the extent to which spouses report ambivalent feelings toward their relationship (alpha $=.87, .67$ for wives and husbands, respectively). Items were answered on a 9 point Likert scale ranging from 1 (very little or not at all) to 9 (very much or extremely). Both McHale et al. (1995) and Volling (1997), using the Braiker and Kelley scales, have found less marital love in families with incongruent patterns of differential affection and favoritism.

Children's emotional outcomes. Mothers and fathers completed the Child Behavior Checklist (CBCL; Achenbach, 1991, 1992) regarding the older siblings' behavior problems. The CBCL- $2 / 3$ version was used for the 2- and 3-year-old older siblings and the CBCL$4 / 18$ version was used for older siblings age 4 and older. Given their young age, CBCL information was not collected on the 16-month-old younger sibling. The CBCL-2 $/ 3$ consists of 99 items that are answered on a 3 point scale $(0=$ not true, $1=$ somewhat or sometimes true, 2 = very true or often true). The CBCL-4/ 18 consists of 100 questions and is rated on a similar scale. Raw scores were converted into $T$ scores for the overall internalizing ( $M s=47.3$ and 49.6 for mothers and fathers, respectively) and exter- 
nalizing dimensions ( $M s=49.2$ and 51.2 for mothers and fathers, respectively) to compare children across the different ages. $T$ scores greater than 70 indicate children in the clinical range (Achenbach, 1991, 1992). Only one child in the current sample had a $T$ score of 70 or greater on the externalizing scales, and only two children had clinical range scores for the internalizing scales. Thus, although there is considerable variability in the range of the children's scores (range $=30-72$ ), the majority of children in this sample are clearly not clinically distressed. The scale scores, then, may be best interpreted as reflecting individual differences in children's emotion regulation abilities with regard to over- or underregulation (Cole, Michel, \& Teti, 1994). Dunn et al. (1990) have reported greater externalizing and internalizing scores for older siblings in middle childhood who are controlled more by their mothers in relation to their younger siblings.

\section{RESULTS}

The first step in the analyses was to examine maternal and paternal differential enjoyment, favoritism, and discipline to determine if the younger sibling was receiving more of a given behavior than the older sibling. The next step was to examine whether parents' reports of differential parental favoritism were related to their reports of differential discipline and enjoyment. Third, maternal and paternal differential treatment were cross-tabulated to identify overall family patterns of differential treatment. Fourth, family relationship quality and children's emotional adjustment measures were examined using 2 (parent) $x$ 3 (family) repeated-measures analysis of variance, with parent as the repeated factor, to examine the correlates of these family patterns. Finally, discriminant function analysis was used to examine the prediction of family groups based on the marital, sibling, and child emotional adjustment variables.

\section{Identifying Family Patterns of Differential Treatment}

Parent reports of differential enjoyment, favoritism, and discipline were used to divide mothers and fathers into three levels of differential treatment: (1) the younger sibling receives more of a given form of treatment, (2) the siblings are treated equally, and (3) the older sibling receives more of a given form of treatment. Table 1 summarizes the results from this analysis.

These results suggest that, in general, the majority of mothers and fathers do not report directing more
Table 1 Distribution of Maternal and Paternal Differential Favoritism, Discipline, and Enjoyment $(N=60)$

\begin{tabular}{lcr}
\hline & Mothers & Fathers \\
\hline Favoritism: & 12 & \\
$\quad$ Younger more & 39 & 9 \\
Equal & 9 & 92 \\
$\quad$ Older more & & \\
Discipline: & 2 & 0 \\
$\quad$ Younger more & 20 & 16 \\
Equal & 38 & 44 \\
$\quad$ Older more & 7 & 5 \\
Enjoyment: & 38 & 41 \\
$\quad$ Younger more & 15 & 14 \\
$\quad$ Equal & & \\
$\quad$ Older more & & \\
\hline
\end{tabular}

of any of the behaviors examined toward the younger sibling in relation to the older sibling. Only in the case of differential favoritism do mothers, if they report favoring a sibling, favor the younger sibling slightly more than the older sibling (12 versus 9 ). Most parents reported equal enjoyment and favoritism for both siblings. In the case of differential discipline, though, if a sibling was disciplined more often, both parents reported disciplining the older sibling more in relation to the younger sibling.

To examine the relations between parents' reports of enjoyment and discipline with favoritism, Fisher's Exact Tests were conducted. These results revealed significant associations between mothers' differential enjoyment and differential favoritism, $p<.05$, and between fathers' reports of differential enjoyment and differential favoritism, $p<.01$. There were no significant associations between mothers' or fathers' reports of differential discipline and their reports of differential favoritism. In sum, favoritism of one child over the other may be reflected in the parents' reports of differential enjoyment, but is not reflected in whether the parent disciplines one child more than another.

Family patterns of differential treatment were created by cross-tabulating maternal and paternal reports of differential treatment (see Table 2). Fisher's Exact Tests revealed no relation between the two parents' reports of differential enjoyment, favoritism, or discipline. An examination of Table 2 suggests that while similar patterns of parental enjoyment and favoritism emerged, a different pattern was found for parental discipline.

Table 2 reveals that 32 families (53\% of the sample) reported a congruent pattern of differential enjoyment, 25 families (42\%) reported an incongruent pattern, and only three families (5\%) reported a comple- 
Table 2 Correspondence between Mothers' and Fathers' Reports of Differential Favoritism, Discipline, and Enjoyment $(N=60)$

\begin{tabular}{lcrc}
\hline & \multicolumn{3}{c}{ Fathers' Reports } \\
\cline { 2 - 4 } Mothers' Reports & $\begin{array}{c}\text { Younger } \\
\text { More }\end{array}$ & Equal & $\begin{array}{r}\text { Older } \\
\text { More }\end{array}$ \\
\hline Younger more favoritism & 3 & 7 & 2 \\
Equal favoritism & 5 & 28 & 6 \\
Older more favoritism & 1 & 7 & 1 \\
Younger more discipline & 0 & 0 & 2 \\
Equal discipline & 0 & 4 & 16 \\
Older more discipline & 0 & 12 & 26 \\
Younger more enjoyment & 1 & 5 & 1 \\
Equal enjoyment & 2 & 27 & 9 \\
Older more enjoyment & 2 & 9 & 4 \\
\hline
\end{tabular}

mentary pattern. When the congruent group was broken down further, it was found that in 27 families ( $45 \%$ of the entire sample) both mothers and fathers reported equal enjoyment of both siblings. In only one family $(2 \%)$ did both parents report enjoying the younger sibling more, and in only four families (7\%) did both parents report enjoying the older sibling more. In the incongruent group, seven families $(12 \%$ of the entire sample) had one parent enjoying the younger sibling more while the other parent reported equal enjoyment, and 18 families $(30 \%)$ had one parent enjoying the older sibling more while the other parent reported equal enjoyment.

Given the significant association between favoritism and enjoyment reported earlier, it was not surprising that a nearly identical pattern of differential favoritism emerged as that found for differential enjoyment. Again, a congruent pattern was reported by mothers and fathers in 32 families $(53 \%$ of the sample), whereas 25 families (42\%) reported an incongruent pattern, and only three families $(5 \%)$ reported a complementary pattern. For the congruent families, both mothers and fathers reported equal favoritism in 28 of the families ( $47 \%$ of the entire sample), favoritism of the younger sibling in three of the families $(5 \%)$, and favoritism of the older sibling in only one of the families (2\%). A breakdown of the incongruent group revealed that one parent favored the younger sibling while the other parent reported equal favoritism in 12 of the families ( $20 \%$ of the entire sample), and one parent favored the older sibling while the other parent reported equal favoritism in 13 of the families (22\%).

Finally, the pattern of differential discipline was quite unlike the groupings for enjoyment and favoritism. Whereas a congruent pattern of differential dis- cipline was reported by 30 families ( $50 \%$ of the sample), only four families ( $7 \%$ of the entire sample) had both mothers and fathers disciplining both children equally. The remaining 26 families in the congruent pattern $(43 \%)$ had both mothers and fathers disciplining the older sibling more, whereas none of the families had both mothers and fathers disciplining the younger sibling more. An incongruent pattern of differential discipline was reported by 28 families $(47 \%$ of the sample). In all 28 of these families, one parent reported disciplining the older sibling more while the other parent reported equal discipline. No families had one parent disciplining the younger sibling more while the other parent reported equal discipline. A complementary pattern of differential discipline was reported by only two families ( $3 \%$ of the sample).

\section{Family Relationship Correlates of Differential Treatment}

Preliminary analyses examined family structure variables (i.e., the age of the older sibling, the age space between the siblings, the gender composition of the sibling dyad, and birth order) as a function of the family patterns of differential treatment. Oneway ANOVAs with family pattern as the betweengroup factor and chi-square analyses revealed no significant differences between family patterns on the basis of any of the family structure variables for any of the group comparisons. Thus, they were not considered further.

To determine whether families that differed on the basis of differential treatment groups also differed with respect to family relationship quality and child behavior, repeated-measures analyses of variance were conducted. Both cell size and conceptual interests determined the family patterns that were included in analyses. Recall that our hypotheses focused primarily on comparisons between congruent and incongruent family types. First, comparisons were made on the basis of differential enjoyment between families in which both parents enjoyed the siblings equally ( $n=27)$, families in which one parent enjoyed the younger sibling more while the other parent reported equal enjoyment $(n=7)$, and families in which one parent enjoyed the older sibling more while the other parent reported equal enjoyment $(n=$ 18). Second, comparisons were made on the basis of differential favoritism between families in which both parents reported equal favoritism $(n=28)$, families in which one parent favored the younger sibling while the other parent reported equal favoritism $(n=$ 12), and families in which one parent favored the older sibling while the other parent reported equal 
favoritism ( $n=13)$. Finally, comparisons were made on the basis of differential discipline between families in which the father disciplined the older sibling more while the mother disciplined both siblings equally $(n=16)$, families in which both parents disciplined the older sibling more $(n=26)$, and families in which the mother disciplined the older sibling more while the father disciplined both siblings equally $(n=12)$. Given the interest in family group differences, parent effects and parent $\times$ group interactions from the repeated-measures analyses of variance will not be discussed.

Family and child correlates of differential enjoyment. Differences in sibling and marital relationships across family patterns of differential enjoyment were examined using 2 (parent) $\times 3$ (family group) repeated-measures analysis of variance with parent as the repeated factor. No significant effects were found for differential enjoyment groups for either the marital or sibling relationship.

$T$ scores for the internalizing and externalizing scales of the Child Behavior Checklist were analyzed using 2 (parent) $\times 3$ (family group) repeatedmeasures ANOVAs with parent as the repeated measure. No significant differences were revealed between differential enjoyment groups on the basis of the older siblings' emotional adjustment.

Family and child correlates of differential favoritism. Results from the 2 (parent) $\times 3$ (family group) repeated-measures ANOVAs with parent as the repeated factor revealed no significant findings for the sibling relationship.

As for the marital relationship, 2 (parent) $\times 3$ (family) repeated-measures ANOVAs revealed a significant family group effect for marital love, $F(2$, $48)=3.21, p<.05$. Tukey's post hoc comparisons suggested that there was significantly more love reported by spouses in the equal treatment group $(M=77.2)$ than in the group in which the older sibling was favored by one parent and the other favored both siblings equally $(M=70.4)$. Spouses in those families in which the younger sibling was favored by one parent and the other parent favored both siblings equally reported less love than the equal treatment group $(M=73.0)$, but this was not significantly different from the means of either of the other family groups.

Results from 2 (parent) $\times 3$ (family group) repeated-measures ANOVAs with regard to the older siblings' emotional adjustment revealed no significant differences.

Family and child correlates of differential discipline. Analyses from 2 (parent) $\times 3$ (family group) repeated-measures ANOVAs with parent as the re- peated factor for the sibling relationship measures revealed significant group effects for the older siblings' positive involvement with the younger sibling, $F(2,47)=3.25, p<.05$, and for the older siblings' rivalry with the younger sibling, $F(2,47)=$ $5.47, p<.01$ (see Table 3). Tukey's post hoc comparisons revealed that in the case of the older sibling's positive involvement with a younger sibling, there was more positive involvement in those families where the father disciplined the older child more often and mother disciplined the children equally than in those families where both siblings received equal discipline from both parents (see Table 3). Similarly, there was significantly greater rivalry by the older sibling toward the younger in those families where both parents disciplined the older sibling more often than in either of the other two family constellations.

With regard to the marital relationship, 2 (parent) $\times 3$ (family group) repeated-measures ANOVAs with parent as the repeated factor revealed a significant group effect for marital conflict, $F(2,94)=4.38$, $p<.05$. Tukey's post hoc comparisons revealed that there was significantly more marital conflict reported in families in which mothers were primarily disciplining the older sibling and fathers were disciplining the two children equally than in those families where the mother disciplined the children equally, but the father disciplined the older sibling more (see Table 3).

Significant group effects for both the internalizing, $F(2,50)=5.98, p<.01$, and externalizing scales, $F(2$, $50)=3.74, p<.05$, were found in the 2 (parent) $\times$ 3 (family group) repeated-measures ANOVAs with parent as the repeated factor. Post hoc comparisons using Tukey's HSD statistic revealed that parents reported significantly more internalizing and externalizing behaviors for older siblings in families where both mothers and fathers disciplined the older sibling than in those families where fathers disciplined the older sibling more frequently and mothers disciplined the two children equally (see Table 3 ).

Additional follow-up analyses. In all prior analyses, the entire sample of 60 families was utilized to examine the correlates of family patterns of differential treatment, even though some of the sibling pairs were first- and second-borns, and other pairs included second- and later-born children. This was done primarily to insure the statistical power of analyses by using the larger sample. However, structural family theory might suggest that the relationship dynamics in families with two children would be very different from those families with two or more children. To examine this possibility, all of the findings were reexamined by conducting 2 (parent) $\times 3$ (fam- 
Table 3 Differential Discipline: Significant Mean Differences for Family Relationships and Child Well-Being

\begin{tabular}{lccc}
\hline & $\begin{array}{c}\text { Both Parents Discipline } \\
\text { Older Sibling More } \\
(n=26)\end{array}$ & $\begin{array}{c}\text { Father Disciplines Older, } \\
\text { Mother Equal Discipline } \\
(n=16)\end{array}$ & $\begin{array}{c}\text { Mother Disciplines Older, } \\
\text { Father Equal Discipline } \\
(n=12)\end{array}$ \\
\hline Older sibling: & & & \\
Positive involvement & $46.5_{\mathrm{a}}$ & $53.0_{\mathrm{b}}$ & $49.1_{\mathrm{a}, \mathrm{b}}$ \\
Conflict & $33.8_{\mathrm{a}}$ & $29.6_{\mathrm{b}}$ & $29.7_{\mathrm{b}}$ \\
Externalizing & $52.9_{\mathrm{a}}$ & $47.1_{\mathrm{b}}$ & $51.2_{\mathrm{a}, \mathrm{b}}$ \\
Internalizing & $51.7_{\mathrm{a}}$ & $44.2_{\mathrm{b}}$ & $49.2_{\mathrm{a}, \mathrm{b}}$ \\
Marital conflict & $22.7_{\mathrm{a}, \mathrm{b}}$ & $19.3_{\mathrm{a}}$ & $25.0_{\mathrm{b}}$ \\
\hline
\end{tabular}

Note: Means with different subscripts are significantly different from one another $(p<.05)$.

ily) ANCOVAs with parent as a repeated factor and birth order of the sibling pair as a covariate. All significant findings reported above remained significant after controlling for the covariate, with the exception of the externalizing score in the differential discipline analysis, which was now only marginally significant, $F(2,49)=2.57, p=.09$.

Several investigators have also suggested that differential treatment in the family may be driven by child effects in that parents are responding to temperamental differences between the siblings (e.g., Dunn \& Stocker, 1989). Thus, differences in the older siblings' emotional adjustment across the differential discipline groups may be due to temperamental differences. To address this possibility, both mothers' and fathers' ratings of the older siblings' temperament using the activity level, anger, social fear, interest, and pleasure scales from the Toddler Behavior Assessment Questionnaire (TBAQ; Goldsmith, 1996) were subjected to a 2 (parent) $\times 3$ (family) repeatedmeasures analysis of variance with parent as the repeated factor using the differential discipline, favoritism, and enjoyment groupings. Results from these analyses were all nonsignificant.

\section{Multivariate Prediction of Differential Treatment Groups}

The analyses to this point have focused primarily on individual dimensions of family relationships and child well-being as they relate to differential treatment groups. In the final analyses, discriminant analysis (DA) was performed to examine whether differential treatment groups could be differentiated using a collective set of independent variables. Because none of the independent variables were significantly different across groups for differential enjoyment and only spouses' reports of marital love revealed differences across differential favoritism groups, the discriminant analysis was limited to the differential
Table 4 Correlations between Independent Variables and Canonical Discriminant Function for Differential Parental Discipline Analysis

\begin{tabular}{lc}
\hline Independent Variables & Function 1 \\
\hline Older sibling externalizing & .793 \\
Older sibling internalizing & .657 \\
Older sibling positive involvement & -.612 \\
Older sibling rivalry/aggression & .549 \\
Marital conflict & .441 \\
\hline
\end{tabular}

discipline groups. To restrict the number of variables used given the sample size, the average of both parents' scores for older sibling conflict, older sibling positive involvement, marital conflict, and the older sibling's externalizing and internalizing scores were used in the DA for differential discipline groups.

The DA for the differential discipline groups revealed that the two canonical discriminant functions accounted for $73.7 \%$ and $26.3 \%$, respectively, of the between-groups variability. However, only the first discriminant function contributed significantly to group differences, Wilks's lambda $=.62, \chi^{2}(10)=$ $23.15, p=.01$. Table 4 presents the correlations between the independent variables and the first canonical discriminant function, which appears to reflect an underlying construct of child dysregulation and family conflict. The means for the three groups on the discriminant function are shown in Table 5 and sug-

Table 5 Canonical Discriminant Function Means as a Function of Differential Discipline Groups

Group

Function 1

1. Mother disciplines older, father disciplines equally

.131

2. Father disciplines older, mother disciplines equally

$-.923$

3. Both parents discipline older 
Table 6 Discriminant Analysis: Classification of Differential Discipline Family Groups

\begin{tabular}{|c|c|c|c|c|}
\hline \multirow[b]{2}{*}{ Group } & \multirow[b]{2}{*}{$N$} & $\begin{array}{l}\text { Mother Disciplines Older, } \\
\text { Father Disciplines Equally } \\
\text { (1) }\end{array}$ & $\begin{array}{l}\text { Father Disciplines Older, } \\
\text { Mother Disciplines Equally } \\
\text { (2) }\end{array}$ & $\begin{array}{l}\text { Both Parents Discipline } \\
\text { Older Sibling } \\
\text { (3) }\end{array}$ \\
\hline & & \multicolumn{3}{|c|}{ Predicted Classifications } \\
\hline 1. & 12 & $5(42 \%)$ & $2(17 \%)$ & $5(42 \%)$ \\
\hline 2. & 16 & $2(12.5 \%)$ & $9(56 \%)$ & $5(31 \%)$ \\
\hline 3. & 26 & $3(11.5 \%)$ & $3(11.5 \%)$ & $20(77 \%)$ \\
\hline
\end{tabular}

Note: Underscored numbers reflect rate of correct classifications.

gest that this discriminant function successfully distinguishes families in which fathers disciplined older children more than their younger children and mothers disciplined the children equally from the other two families (i.e., both parents discipline the older more than the younger and those wherein mother disciplines the older more and father disciplines both children equally). Families in which fathers are disciplining the older siblings more often and mothers discipline children equally are distinguished primarily from the other two family groups in that they are less likely to be characterized by emotionally dysregulating behavior of the older child and family conflict. Using the results from this internal classification analysis, $63 \%$ of the cases were correctly classified. However, classification rates varied depending on the family group: $41.7 \%$ of the families in which mother disciplined the older sibling and father disciplined children equally were correctly classified, $56.3 \%$ of those families in which fathers disciplined the older children and mothers disciplined the children equally were correctly classified, and, finally, $76.9 \%$ of the families in which both parents disciplined the older siblings more often were correctly classified (see Table 6).

\section{DISCUSSION}

Mothers' and fathers' reports of differential enjoyment, favoritism, and discipline and their significance to family and child functioning were the focus of the current study. In an effort to replicate the findings of McHale et al. (1995) and Volling (1997), patterns of differential treatment were examined to determine if parents directed more of a given behavior toward the younger sibling and to identify congruent, incongruent, and complementary family configurations of differential treatment in early childhood. Several interesting findings with regard to parents' differential treatment in early childhood were found that were both consistent and inconsistent with the earlier studies.

First, the majority of mothers and fathers of these very young children did not direct more enjoyment, favoritism, or discipline toward the younger sibling, as has been reported in many past studies with older children and adolescents (e.g., Brody et al., 1992; McHale et al., 1995; Stocker et al., 1989). In only one case, if favoritism was shown, did it appear that mothers favored the younger sibling. Both parents were most likely to report equal enjoyment and favoritism toward both siblings, and actually reported disciplining the older sibling more than the younger sibling. These findings are in contrast to many of the earlier reports with older children in which parents displayed more affection and discipline to the younger sibling in the family, but are consistent with those reported by Volling (1997) in which mothers and fathers of preschool siblings disciplined the older sibling in the family more often than their younger brother or sister. Parents, it seems, are sensitive to the developmental differences between their young children (Dunn, Plomin, \& Daniels, 1986; Dunn, Plomin, \& Nettles, 1985) and use more control with the older preschool child than with the younger toddler sibling in the family (Dunn \& Kendrick, 1982). Indeed, the developmental differences between children of this age would suggest that parents may be appropriate in disciplining and controlling the stronger and more developmentally mature child. The family patterns overall suggested that in nearly all families, some strategy was employed in which the older sibling received more discipline, whether it was from both parents or only from one parent. Thus, these findings point to the developmental nature of differential parental treatment and suggest that findings from one stage of childhood cannot be generalized to other developmental periods.

A developmental explanation is further supported by Volling's (1997) findings in a sample of preschool 
siblings who were, on average, 2 years older than those studied here. Different constellations of family patterns of differential treatment were found in that study examining 3.5- and 6-year-old siblings than those in the current study with children approximately 1.5 and 4 years of age. Parents in the Volling (1997) study reported disciplining both children equally and disciplining the older sibling at approximately the same rate, whereas parents in the current study rarely reported disciplining both children equally and almost always directed more discipline to the older sibling. Collectively, these findings suggest that changes in differential discipline may be occurring even during the short period of early childhood that most likely coincide with the dramatic changes taking place in children's developmental abilities from infancy into the preschool years. Needless to say, an important direction for future research will be to study within-family differences in parents' differential treatment longitudinally, allowing for an examination of the change in differential treatment patterns across different developmental periods of childhood.

Another goal of the current research was to determine whether parents' reports of favoritism were consistent with their reports of differential discipline and enjoyment. It was the case that for both mothers and fathers the enjoyment of one child over another was also related to favoritism for that child. Yet, consistent with Volling (1997), neither parents' reports of differential discipline were associated with their reports of favoritism. So, even though parents disciplined the older sibling at a much higher rate than they did the younger toddler, they did not equate this with favoring the younger sibling. At this developmental period of early childhood, then, disciplining the older sibling more than a younger sibling may reflect a normative pattern of parenting rather than parental favoritism.

\section{Family Patterns of Differential Parental Treatment}

When the correspondence between mothers' and fathers' reports of differential treatment were divided into family patterns, a tendency toward congruence (both parents treating their children similarly) for all three dimensions was identified. Although this finding was consistent with $\mathrm{McHale}$ et al. (1995) using an older sample, the pattern of congruence was different depending on the dimension examined. For example, in the case of differential enjoyment and favoritism, parents were most likely to report equal treatment of both siblings, but with dif- ferential discipline, both mothers and fathers were most likely to report disciplining the older sibling, not the younger sibling.

Interestingly, a complementary pattern of differential treatment (one parent showing more of a given behavior toward one sibling while the other parent shows more of that behavior towards the other sibling) was rarely reported, which is consistent with the two earlier studies documenting the relatively low occurrence of these family constellations when examining discipline or affection in the family. In the current study, only three families fit this pattern for enjoyment and favoritism, and two families fit this pattern for discipline.

A sizable group of families also reported incongruent patterns of differential treatment (one parent treating the siblings equally and the other parent showing more of a given behavior toward one sibling) on all three dimensions. In these groups, when differential enjoyment was identified it was more often in the direction of the older sibling, and when differential discipline was identified, it was always in the direction of the older sibling being disciplined more often than the younger sibling. In the case of differential favoritism, if favoritism was reported, mothers did report a slight tendency to favor the younger toddler. The majority of these family patterns are in contrast to those identified by McHale et al. (1995) with a sample of older children and adolescents in which differential treatment was most often directed toward the younger sibling. Again, differential parental treatment most likely changes over time to reflect different patterns from infancy to adolescence.

Family and Child Well-Being Correlates of Differential Treatment

In addition to identifying the family patterns of differential enjoyment, favoritism, and discipline, another aim was to determine if congruent and incongruent family patterns also differed in terms of the sibling relationship, the marital relationship, and the older siblings' emotional well-being. Family structure variables (e.g., birth order, the age of the older sibling, the age space between the siblings, gender) were not significantly related to any of the family groups of differential treatment. This lack of findings may be due, in part, to the small sample employed and the fact that in several instances the cell sizes were relatively small for statistical comparisons. McHale et al. (1995), for instance, with a larger sample of older children did find relations between the 
gender composition of the sibling pairs and their differential treatment groups. In families with older sister-younger brother pairs, both mothers and fathers were more likely to report disciplining the younger boy. Similarly, it was rare for younger brothers in older sister-younger brother dyads to be the recipients of more parental affection than their older sisters. Another possibility, however, is that structural family variables such as gender do not account for as much variation in differential parental treatment patterns at earlier ages as they do in the later years of childhood or adolescence.

In contrast to the findings with the family structure variables, family relationship quality did vary as a function of differential treatment patterns. For instance, parents reported more feelings of love in their marital relationship when both parents reported equal favoritism than when one parent favored the older sibling and the other parent showed equal favoritism. This suggests that a congruent pattern of favoritism, in which both parents favor the children equally, is associated with better marital relationships, whereas an incongruent pattern may reflect the formation of a parent-child alliance as a result of marital distress. This association between marital dissatisfaction and incongruent family patterns was found only for favoritism and not for incongruent patterns of differential discipline. This is consistent with the only two other studies that have looked at family patterns of differential treatment and marital relationships (see McHale et al., 1995, and Volling, 1997). Thus, it seems that marital distress and differential parental treatment are related if sibling favoritism is at issue, but marital distress does not appear to characterize incongruent patterns of differential discipline, and this appears to be the case in families with preschool and school-age children.

The most interesting findings, however, were found in the case of differential discipline. The results were partially inconsistent with past findings suggesting that the child who is disciplined more often shows more negative behavior toward their sibling and has poorer adjustment outcomes. In regard to the sibling relationship, parents reported that the older sibling showed more positive involvement and less conflict toward the younger sibling in families where the mother disciplined the children equally while the father disciplined the older sibling more versus families where both parents disciplined the older sibling more. It is important to note that older siblings showed the most negative behavior toward the younger sibling and the highest internalizing and externalizing behaviors when both parents disciplined them more, but older siblings showed the most posi- tive behavior toward their sibling and the lowest internalizing and externalizing behaviors when only the father disciplined them more. Therefore, it does not always appear to be the case that the child who receives more parental discipline than their sibling experiences greater adjustment difficulties or is in greater conflict with their sibling.

In terms of the marital relationship, parents also reported more marital conflict in those families where the mother disciplined the older sibling more while the father showed equal discipline versus families where the father disciplined the older sibling more while the mother showed equal discipline. These results point toward the importance of further breaking down the family patterns past congruent and incongruent patterns. In the present study, there was a significant difference between the two incongruent groups, suggesting that it was important to know which parent was disciplining the older child more often. In the case of the older siblings' emotional well-being, mothers and fathers reported more internalizing and externalizing behaviors in families where both parents disciplined the older sibling more than in families where the father disciplined the older sibling more while the mother showed equal discipline. It is not possible to infer casual relations from these findings, but there are two possible explanations. First, older siblings may indeed react to both parents disciplining them more often and show more emotional difficulties as a result. Alternatively, parents may find it necessary to discipline an older child exhibiting more emotionally disruptive behaviors.

The most optimal family system with regard to both family relationship correlates and the older child's well-being was when the father disciplined the older sibling more while the mother disciplined both children equally. In interpreting these findings, it is important to remember that these families may still be adjusting to the transition period following the birth of a baby sibling, and that mothers may be more responsible for the direct care of the younger toddler. Kreppner, Paulsen, and Schuetze (1982) suggested that after the birth of a sibling, some families rearranged the division of child care such that the father was expected to be more involved with the older child while the mother was busy caring for the new baby. At 16 months, the younger siblings in the current study were still at an age where they required a great deal of direct care. It appears that when the father was taking the role of disciplinarian with the older sibling, the mother was free to direct more of her time and attention to the care of the younger sibling, which in turn was related to less marital conflict. Recall that more marital conflict 
was reported by spouses in those families where the mother disciplined the older sibling more often while the father showed equal discipline. In this family pattern, mothers were not only caring for the younger infant, but they were also expected to take on the role of disciplinarian for the older child. This greater maternal involvement combined with low levels of father involvement during a time of transitional stress may have accounted, in part, for the higher levels of conflict between spouses in these families. Alternatively, marital conflict between spouses may lead to the husband withdrawing from family interaction (Gottman, 1994), which, in turn, could result in the family pattern where mothers find themselves more involved in the discipline of the older sibling.

The differential enjoyment groups did not differ significantly on any sibling, marital, or child wellbeing variables. Indeed, most of the significant findings were found in the case of differential discipline. Because the toddler period is a time when parents are busy directing their attention to issues of control and discipline (Belsky, Crnic, \& Gable, 1995), differential discipline may be more influential in predicting family relationship quality and child adjustment than differential enjoyment. Perhaps when these children enter school and become more selfsufficient, parents will be able to devote far less time to child care and behavioral management, and have more time available to enjoy the children's extracurricular and after-school activities.

\section{Family Distress or Normative Childrearing}

Let us return to the question introduced earlier: When does differential parental treatment reflect distress in the family system and when does it reflect a normative parenting strategy? We by no means expect to answer this question definitively, nor do we espouse that our response will apply beyond those aspects of parenting examined here or, in many respects, the period of early childhood. Furthermore, the fact that the children in our sample were relatively well functioning also imposes limits on how far we can discuss distress and dysfunction in the family. This limitation applies not only to the current work, but to nearly all studies examining the relation between differential parental treatment and child well-being. Few existing studies have examined these issues in samples other than well-functioning, predominantly middle-class families, although terms such as "psychological adjustment" and "behavior problems" are used quite liberally in describing these children's outcomes. Future investigations are needed in which these issues are addressed in clinical as well as nonclinical populations. Finally, any comments with respect to normative development and differential parental treatment must be restricted to parents of white, middle-class, maritally intact families. Future research is still needed that addresses these issues in families of color and other diverse family forms (e.g., stepfamilies).

With these caveats in mind, we now turn our attention to those consistent findings that have started to emerge across the few studies that have examined differential parental treatment from a family-level analysis. With respect to family distress, there are several points that need to be underscored. First, family and child distress were not detected by simply dividing families into congruent versus incongruent patterns. An incongruent pattern of differential favoritism, for example, was associated with less marital love between spouses, which provided some support for our hypothesis that parent-child alliances may have formed in these incongruent family systems. In contrast, congruent family situations in which both mothers and fathers favored the two siblings equally were those in which spouses reported the greatest amount of marital love. In the case of discipline, though, it was an incongruent pattern that was related to better family and child functioning and a congruent pattern that was associated with the most family conflict and emotional dysregulation for the older sibling. This is related to the second point to be underscored: Congruence and incongruence relate to family and child distress differently depending on the dimension of parenting examined. Incongruent favoritism (at least in one instance) was associated with marital distress, whereas incongruent discipline (at least in one instance) was associated with family harmony. A third consideration in a discussion of family distress is a question of "whose distress" and which aspect of the family system is being addressed (e.g., the marital versus parent-child versus sibling subsystems). Distress may be evident in the marital subsystem, but not express itself in all children in the family, or children may express emotional upset in some family systems without any noticeable difference in marital quality. Older siblings exhibited the most emotionally dysregulating behavior when both parents directed more discipline toward them. The follow-up analysis suggested that older children did not differ temperamentally across the differential discipline groups, yet we cannot know for certain without longitudinal data whether these children are reacting to their parents' dual control or whether parents are reacting to the children's disruptive behavior. In any case, the family pattern 
here is remarkably similar to that of detouring families described by Minuchin (1974), in which parents with marital difficulties "detour" around their own conflicts and deflect their attention onto the problems or special needs of the child. In a recent study comparing detouring, triangulated, and cohesive families, Kerig (1995) found that spouses' marital adjustment scores did not differ between the detouring and cohesive families, but the children in the detouring families had the highest internalizing and externalizing scores. This picture is very much in line with the congruent families in the current study in which both parents discipline an older sibling with high externalizing and internalizing scores, but do not differ with respect to marital conflict scores from the incongruent families where the children are least likely to express emotional dysregulation. Without further empirical study, we do not know whether the family dynamics associated with this congruent pattern of discipline are unique to the developmental age period under study or will eventually describe similar family constellations across childhood. Most likely, the children's developmental level and family patterns of differential discipline will interact to determine children's emotional outcomes. Recall that McHale et al. (1995) found that older and younger siblings in the preadolescent and adolescent period did not react similarly to the same pattern of differential treatment (i.e., being the recipient of both parents' discipline).

In response to the second half of the question of what may denote a normative childrearing strategy during the early childhood years, we turn to two sets of findings from the current work. First, parents of these very young children almost without exception reported that they disciplined their older child more than the younger sibling in the family. This overall tendency would suggest that parents may find it normative to direct more control to older preschool children in the family who are clearly farther along in their intellectual, social, and emotional skills than their younger toddler siblings. Yet, this general tendency was qualified further by our analysis of familylevel patterns and, specifically, an examination of the quality of the marital relationship. It appears that fathers' involvement in the family as a disciplinarian at this time is critically important, not only for the child's emotional well-being, but for the well-being of the marital relationship as well. Spouses in families where fathers disciplined their older siblings more often, while the mother dispensed discipline equally, not only reported less marital conflict, but their preschool children also expressed less emotionally disruptive behavior and directed less hostile and more positive behaviors to their younger siblings. Again, without further study, we do not know whether this family dynamic is unique to the period of the family life cycle characterizing these families (i.e., the transition to the birth of a sibling) or will eventually describe similar congruent and incongruent family configurations across the family life cycle.

In sum, the overall findings of this study suggest that future investigations of the nonshared family environment should take into account the developmental level of the children being studied and the family configurations of differential parental treatment when interpreting results. Although parental favoritism may be associated with family distress and children's emotional dysregulation throughout childhood, different periods of childhood present different challenges to parents, and, as a result, disciplining strategies should be expected to change over time to coincide with the rapid changes in children's developmental abilities (Brody \& Stoneman, 1994). As such, caution needs to be exercised when generalizing results about differential parental treatment from one period of childhood to that of another period of childhood.

\section{ACKNOWLEDGMENTS}

This research was supported by the Horace H. Rackham School of Graduate Studies and the Office of the Vice President for Research at the University of Michigan. Portions of this research were submitted in fulfillment of the second author's honors thesis.

\section{ADDRESSES AND AFFILIATIONS}

Corresponding author: Brenda L. Volling, Department of Psychology, University of Michigan, $525 \mathrm{E}$. University, Ann Arbor, MI 48109-1109; e-mail: volling@umich.edu. Julie L. Elins is at the California School of Professional Psychology.

\section{REFERENCES}

Achenbach, T. M. (1991). Manual for the Child Behavior Checklist/4-18 and 1991 Profile. Burlington: University of Vermont, Department of Psychiatry.

Achenbach, T. M. (1992). Manual for the Child Behavior Checkist/2-3 and 1992 Profile. Burlington: University of Vermont, Department of Psychiatry.

Belsky, J., Crnic, K., \& Gable, S. (1995). The determinants of coparenting in families with toddler boys: Spousal differences and daily hassles. Child Development, 66, 629-642.

Belsky, J., Woodworth, S., \& Crnic, K. (1996). Trouble in the second year: Three questions about family interaction. Child Development, 67, 556-578.

Braiker, H., \& Kelley, H. H. (1979). Conflict in the develop- 
ment of close relationships. In R. Burgess \& T. Huston (Eds.), Social exchange in developing relationships (pp. 135168). New York: Academic Press.

Brody, G., \& Stoneman, Z. (1994). Sibling relationships and their association with parental differential treatment. In E. M. Hetherington, D. Reiss, \& R. Plomin (Eds.), Separate social worlds of siblings: The impact of nonshared environment on development (pp. 129-142). Hillsdale, NJ: Erlbaum.

Brody, G., Stoneman, Z., \& Burke, M. (1987). Child temperaments, maternal differential behavior, and sibling relationships. Developmental Psychology, 23, 354-362.

Brody, G., Stoneman, Z., \& McCoy, J. K. (1992). Associations of maternal and paternal direct and differential behavior with sibling relationships: Contemporaneous and longitudinal analyses. Child Development, 63, 82-92.

Brody, G., Stoneman, Z., \& McCoy, J. K. (1994). Forecasting sibling relationships in early adolescence from child temperaments and family processes in middle childhood. Child Development, 65, 771-784.

Bryant, B., \& Crockenberg, S. (1980). Correlates and dimensions of prosocial behavior: A study of female siblings with their mothers. Child Development, 51, 354-362.

Christensen, A., \& Margolin, G. (1988). Conflict and alliance in distressed and nondistressed families. In $R$. Hinde \& J. Stevenson-Hinde (Eds.), Relationships within families: Mutual influences. New York: Oxford University Press.

Cole, P. M., Michel, M. K., \& Teti, L. O. (1994). The development of emotion regulation and dysregulation: A clinical perspective. In N. A. Fox (Ed.), The development of emotion regulation: Biological and behavioral considerations (pp. 73-100). Monographs of the Society for Research in Child Development, 59(2-3, Serial No. 24).

Conger, K. J., \& Conger, R. D. (1994). Differential parenting and change in sibling differences in delinquency. Journal of Family Psychology, 8, 287-302.

Crockenberg, S., \& Littman, C. (1990). Autonomy as competence in 2-year-olds: Maternal correlates of child defiance, compliance, and self-assertion. Developmental Psychology, 26, 961-971.

Daniels, D., Dunn, J., Furstenberg, F., \& Plomin, R. (1985). Environmental differences within the family and adjustment differences within pairs of adolescents. Child Development, 56, 764-774.

Daniels, D., \& Plomin, R. (1985). Differential experience of siblings in the same family. Developmental Psychology, 21, 747-760.

Deal, J. E. (1996). Marital conflict and differential treatment of siblings. Family Process, 35, 333-346.

Dunn, J. F., \& Kendrick, C. (1982). Siblings: Love, envy, \& understanding. Cambridge, MA: Harvard University Press.

Dunn, J., Plomin, R., \& Daniels, D. (1986). Consistency and change in mother's behavior toward young siblings. Child Development, 57, 348-356.

Dunn, J., Plomin, R., \& Nettles, M. (1985). Consistency of mother's behavior toward infant siblings. Developmental Psychology, 21, 1188-1195.

Dunn, J., \& Stocker, C. (1989). The significance of differ- ences in siblings' experiences within the family. In $\mathrm{K}$. Kreppner \& R. Lerner (Eds.), Family systems and life-span development (pp. 289-301). Hillsdale NJ: Erlbaum.

Dunn, J., Stocker, C., \& Plomin, R. (1990). Non-shared experiences within the family: Correlates of behavior problems in middle childhood. Development and Psychopathology, 2, 113-126.

Goldsmith, H. H. (1996). Studying temperament via construction of the Toddler Behavior Assessment Questionnaire. Child Development, 67, 218-135.

Gottman, J. M. (1994). What predicts divorce? The relationship between marital processes and marital outcomes. Hillsdale, NJ: Erlbaum.

Haley, J. (1967). Towards a theory of pathological systems. In G. Zuk \& I. Nagy (Eds.), Family therapy and disturbed families. Palo Alto, CA: Science and Behavior Books.

Hetherington, E. M. (1988). Parents, children, and siblings: Six years after divorce. In R. Hinde \& J. StevensonHinde (Eds.), Relationships within families: Mutual influences (pp. 311-331). New York: Oxford University Press.

Hetherington, E. M., \& Clingempeel, W. G. (1992). Coping with marital transitions: A family systems perspective. Monographs of the Society for Research in Child Development, 57(2-3, Serial No. 227).

Kerig, P. K. (1995). Triangles in the family circle: Effects of family structure on marriage, parenting, and child adjustment. Journal of Family Psychology, 9, 28-43.

Kopp, C. B. (1982). The antecedents of self-regulation: A developmental perspective. Developmental Psychology, 18, 199-214.

Kopp, C. B. (1992). Emotional distress and control in young children. New Directions for Child Development, 55, 41-56.

Kreppner, K., Paulsen, S., \& Schuetze, Y. (1982). Infant and family development: From triads to tetrads. Human Development, 25, 373-391.

Kuczynski, L., \& Kochanska, G. (1990). Development of children's noncompliance strategies from toddlerhood to age 5. Developmental Psychology, 26, 398-408.

McGuire, S., Dunn, J., \& Plomin, R. (1995). Maternal differential treatment of siblings and children's behavioral problems: A longitudinal study. Development and Psychopathology, 7, 515-528.

McHale, S. M., Crouter, A. C., McGuire, S. A., \& Updegraff, K. A. (1995). Congruence between mothers' and fathers' differential treatment of siblings: Links with family relations and children's well-being. Child Development, 66 , 116-128.

Minuchin, S. (1974). Families and family therapy. Cambridge, MA: Harvard University Press.

Plomin, R., \& Daniels, D. (1987). Why are children in the same family so different from one another? Behavioral and Brain Sciences, 10, 1-16.

Reiss, D., Plomin, R., Hetherington, E. M., Howe, G., Rovine, M., Tryon, A., \& Hagan, M. S. (1994). The separate worlds of teenage siblings: An introduction to the study of the non-shared environment and adolescent development. In E. M. Hetherington, D. Reiss, \& R. Plomin (Eds.), Separate social worlds of siblings: Importance of nonshared environment on development (pp. 63-110). Hillsdale, NJ: Erlbaum. 
Rutter, M. (1987). Psychosocial resilience and protective mechanisms. American Journal of Orthopsychiatry, 57, 316-331.

Sameroff, A. J., \& Seifer, R. (1983). Familial risk and child competence. Child Development, 54, 1254-1268.

Schaefer, E., \& Edgerton, M. (1981). The sibling inventory of behavior. Chapel Hill: University of North Carolina.

Stocker, C. M. (1993). Siblings' adjustment in middle childhood: Links with mother-child relationships. Journal of Applied Developmental Psychology, 14, 485-499.

Stocker, C. M. (1995). Differences in mothers' and fathers' relationships with siblings: Links with children's behavior problems. Development and Psychopathology, 7, 499-513.
Stocker, C.M., Dunn, J., \& Plomin, R. (1989). Sibling relationships: Links with child temperament, maternal behavior, and family structure. Child Development, 60 , 715-727.

Teti, D. M., \& Ablard, K. E. (1989). Security of attachment and infant-sibling relationships: A laboratory study. Child Development, 60, 1519-1528.

Volling, B. L. (1997). The family correlates of maternal and paternal perceptions of differential treatment in early childhood. Family Relations, 46, 227-236.

Volling, B. L., \& Belsky, J. (1992). The contribution of mother-child and father-child relationships to the quality of sibling interaction: A longitudinal study. Child Development, 63, 1209-1222. 